\title{
ANALISIS SIFAT MEKANIK LAS TIG PADA PLAT ALUMINIUM SERI 5 DENGAN VARIABEL KUAT ARUS 65; 70; 75 A UNTUK MANUFAKTUR KENDARAAN AIR SAMPAN (CANOE)
}

\author{
Andika Wisnujati \\ Program Studi D3 Teknik Mesin, Program Vokasi Universitas Muhammadiyah Yogyakarta \\ Jl. Lingkar Selatan, Tamantirto, Kasihan, Bantul, DIY; Telp 087739255515 \\ e-mail: andika_wisnujati@yahoo.com
}

\begin{abstract}
In general, water vehicles or water transport commonly called canoes are still used in villages for fishermen to fish in the sea and in rivers. Aluminum alloy in this research using Aluminum series 5. Background of this research is to analyze the strength of TIG weld (Tungsten Inert Gas) connection in the canoe to get reliable samples and no leakage. In high TIG welding the low temperature is determined by the high-low of the electric current being flowed. The aluminum plate for the canoe is subjected to material composition testing and tensile testing to determine the physical and mechanical properties of the TIG welding joints on the aluminum series 5. TIG welding with the current variable 65, 70 and 75 Ampere. Testing specimens of $2 \mathrm{~mm}$ thick with dimensions of $24 \times 16 \mathrm{~cm}$ where the electric arc flame is generated by tungsten electrodes (non-feeding electrodes) with metal workpieces. Test results obtained include that welding on aluminum series 5 is done with AC current (Alternating Current) due to the action of cleaning the metal surface is greater. Thin metal work, TIG welding can be used without metal filler. Material composition test showed that aluminum content of $97,76 \%$ and magnesium main addition element equal to $1.753 \%$. In tensile testing, the strong variations of current used to connect aluminum plates are 65, 70, and 75 Ampere produce different tensile strength. The highest tensile strength is generated on plate grafting using a strong current of 75 Ampere with a yield of $165.91 \mathrm{MPa}$. This is because with a strong current of $75 \mathrm{~A}$, the welding liquid enters and fuses into the center of the aluminum, resulting in a strong welding joint.
\end{abstract}

Keywords: Aluminum Series 5, Las TIG, Physical Properties and Mechanical

\section{PENDAHULUAN}

Pada zaman dahulu, orang bermukim terletak di pinggiran laut atau sungai. Hal ini disebabkan orang memerlukan air untuk kegunaan harian dan bercocok tanam. Kemudian, sungai dan laut dijadikan jalan perhubungan yang dikenali sebagai jalan air. Pengangkutan air merupakan pengangkutan kedua terpenting selepas pengangkutan darat. Sungai-sungai ini berperanan menghubungkan kawasan hulu dan hilir. Orang Melayu pada zaman dahulu menggunakan rakit, perahu dan sampan. Mereka akan berdagang ke kawasan-kawasan lain menggunakan sampan dan rakit. Mereka menghilir ke muara-muara sungai yang besar.

Pada pengelasan Tungsten Inert Gas tinggi rendah temperatur salah satu ditentukan oleh tinggi rendah arus listrik yang dialirkan. Perubahan struktur mikro logam salah satu dampak berpengaruh pada kekuatan impak logam. Perubahan kekuatan impak pada hasil pengelasan dua logam yang berbeda juga akan berbeda bila dibandingkan dengan pengelasan dua logam sejenis.

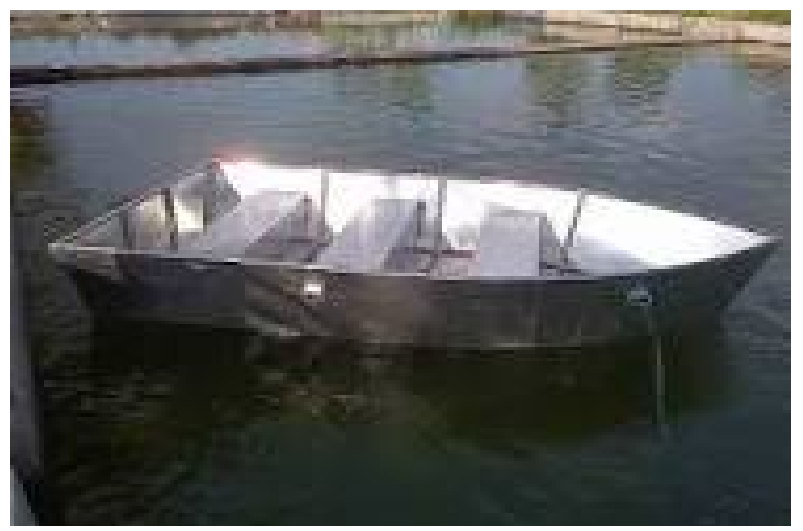

Gambar 1. Sampan (Canoe) 
Latar belakang di lakukan penelitian analisis kekuatan canoe untuk kendaraan air ini adalah menjamin canoe bila dipakai wisata di sungai, embung dan kolam dalam keadaan handal dan tidak mengakibatkan kebocoran dan atau deformasi, sehingga mencelakakan penumpang canoe. Analisis dilakukan dengan pengujian kekuatan bahan yang digunakan yaitu pengujian tarik untuk menganalisis tegangan-tegangan yang terjadi khusus dibagian pada sambungan las. Penelitian ini dibatasi oleh beberapa hal, antara lain: proses pengelasan menggunakan metode las Tungsten Inert Gas atau las dengan pelindung gas; material kerja adalah pelat aluminium seri 5 dengan tebal 2 mm; uji material rnenggunakan Universal Tensile Machine (Mesin Uji Tarik) dan Alat uji bahan atau komposisi (Spectrometer) mengunakan peralatan yang disebut dengan Optical Emission Spectroscopy (OES). Tujuan dilakukan penelitian ini adalah menganalisis kekuatan canoe dan hasil analisis diharapkan memberi petunjuk pada bagian canoe yang menderita beban paling besar dapat dilakukan penguatan konstruksi, sehingga canoe yang di manufaktur mempunyai kehandalan baik.

Penelitian tentang pengaruh pengelasan berulang tiga kali dan variasi ampere terhadap kekuatan tarik material baja ST 42, diperoleh besar kecil kekuatan tarik pada penelitian ini banyak dipengaruhi oleh variasi masukan panas ampere yang menyebabkan kekuatan tarik baja ST 42 menurun. Dari semua variasi ampere yang mernpunyai kekuatan tarik terbesar adalah 90A [1]. Menurut Fiskan, tentang pengaruh variasi kampuh terhadap kekuatan tarik hasil pengelasan tungsten inert gas pada baja karbon rendah ST 37 [2]. Penelitian ini bertujuan untuk mengetahui kekuatan tarik hasil pengelasan tungsten inert gas (TIG) pada baja karbon rendah ST 37. Dari hasil pengujian yang telah dilakukan, diketahui bahwa kekuatan tarik tertinggi terdapat pada raw material dengan nilai rata-rata sebesar 493,02 $\mathrm{MPa}$.

\section{METODE PENELITIAN}

Metode yang digunakan pada penelitian tentang analisis sifat mekanik las tungsten inert gas (TIG) pada aluminium seri 5 untuk manufaktur kendaraan air canoe antara lain sebagai berikut:

\section{Alat}

Beberapa alat yang digunakan antara lain:

a. Mesin las AC

b. Tabung gas lindung

c. Regulator gas lindung

d. Flowmeter gas

e. Selang gas

f. Kabel elektroda

g. Elektroda tungsten

h. Mesin uji tarik Servopulser Shimadzu, digunakan untuk menguji tarik dari suatu material.

\section{Bahan}

a. Material yang digunakan dalam pengujian tarik ini adalah pelat aluminium dengan tebal $2 \mathrm{~mm}$ dan berukuran persegi $30 \mathrm{~mm}$ x $30 \mathrm{~mm}$.

b. Material yang digunakan untuk pengelasan adalah pelat aluminium dengan tebal $2 \mathrm{~mm}$ dengan ukuran semula pelat $240 \mathrm{~mm}$ x $160 \mathrm{~mm}$

\section{Tempat Penelitian}

Pengujian dilakukan di Laboratorium Bahan Teknik, Departemen Teknik Mesin dan Industri Fakultas Teknik Universitas Gadjah Mada, Yogyakarta.

\section{HASIL DAN PEMBAHASAN}

Aluminium merupakan logam ringan mempunyai ketahanan korosi yang baik, hantaran listrik yang baik serta sifat-sifat baik yang lain sebagai sifat logam. Kekuatan mekanik yang sangat meningkat dengan penambahan $\mathrm{Cu}, \mathrm{Mg}, \mathrm{Mn}, \mathrm{Zn}, \mathrm{Ni}$ dan sebagainya, material ini digunakan di bidang yang luas bukan saja untuk peralatan rumah tangga tapi juga dipakai untuk keperluan 
material pesawat terbang, mobil, konstruksi serta sampan atau canoe yang sedang di bahas dalam penelitian ini. Paduan Alumunium-Magnesium (Al-Mg) mempunyai ketahanan korosi yang sangat baik, sejak lama disebut hidronalim dan dikenal sebagai paduan yang tahan korosi. $\mathrm{Cu}$ dan $\mathrm{Fe}$ sangat berbahaya bagi ketahanan korosi terutama $\mathrm{Cu}$ sangat memberikan pengaruh ketahanan korosi. Paduan Alumunium-Magnesium 5xxx yang diambil adalah paduan antara $(4,5 \% \mathrm{Mg}) \mathrm{kuat}$ dan mudah dilas oleh karena itu sekarang dipakai sebagai bahan pembuatan sampan atau canoe.

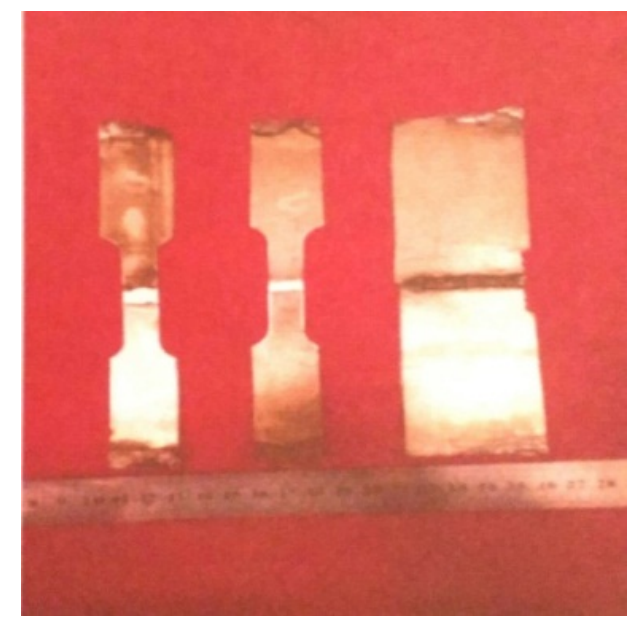

Gambar 2. Spesimen uji tarik

\section{Pengujian Komposisi Bahan}

Pengujian komposisi material ini dilakukan untuk memastikan bahwa pemilihan bahan yang digunakan untuk pengujian sesuai dengan yang diharapkan. Pengujian ini menggunakan peralatan yang disebut dengan Optical Emission Spectroscopy (OES) alat ini bekerja dengan menggunakan prinsip pantulan cahaya ke spesimen uji. Pantulan cahaya dari unsur akan langsung di-input ke dalam komputer dan akan dihasilkan data hasil komposisi seperti Tabel 1 dan dilakukan di Universitas Gadjah Mada Yogyakarta. Dari hasil pengujian yang dilakukan didapatkan hasil seperti berikut ini:

\begin{tabular}{cc} 
Tabel 1. Hasil uji komposisi bahan \\
\hline Unsur & $\mathbf{( ~ \% ) ~}$ \\
\hline $\mathrm{Si}$ & 0.04 \\
$\mathrm{Fe}$ & 0.2243 \\
$\mathrm{Cu}$ & 0.0170 \\
$\mathrm{Mn}$ & 0.0108 \\
$\mathrm{Mg}$ & 1.7531 \\
$\mathrm{Zn}$ & 0.0295 \\
$\mathrm{Ti}$ & 0.0161 \\
$\mathrm{Cr}$ & 0.1526 \\
$\mathrm{Ni}$ & 0.0003 \\
$\mathrm{~Pb}$ & 0.0009 \\
$\mathrm{Sn}$ & 0.0026 \\
$\mathrm{Al}$ & 97.76
\end{tabular}

Hasil pengujian spectrometer pada Tabel 1 di atas memperlihatkan bahwa kandungan aluminium sebesar (Al) $97.76 \%$ dan unsur alloy penambah utama yang terdapat pada paduan ini merupakan Magnesium (Mg) yang memiliki prosentase sebesar 1.7531\%. Dari data tersebut maka bisa disimpulkan bahwa aluminium tersebut merupakan aluminium seri 5 karena memiliki dan unsur alloy penambah utama yang terdapat pada paduan ini merupakan Magnesium (Mg) yang memiliki kadar $1.7531 \%$. 


\section{Pengujian Tarik}

Sifat mekanik yang dipelajari adalah kekuatan tarik. Pengujian tarik dilakukan untuk mengetahui tegangan tarik, tegangan luluh dan regangan pada bahan pembuatan poros berulir (screw). Kekuatan tarik merupakan kemampuan bahan untuk menerima beban tarik. Pengujian dilakukan dengan menggunakan mesin uji tarik Servopulser Shimadzu dengan cara menjepit sampel dengan kuat dan beban diberikan secara kontinyu sampai sampel tersebut putus. Sifat-sifat mekanis yang diharapkan untuk diketahui adalah kekuatan (tegangan) tarik, kekuatan luluh dan regangan dengan perhitungan menggunakan rumus [1-2]:

$\sigma u=\frac{P u}{A o}$

dengan:

$\sigma \mathrm{u}$ : Tegangan Tarik $\left(\mathrm{N} / \mathrm{mm}^{2}\right)$

$\mathrm{Pu}$ : Beban Tarik (KN)

Ao : Luas Penampang Tarik mula-mula $\left(\mathrm{mm}^{2}\right)$

$\varepsilon=\frac{L-L o}{L o} \times 100 \%$

dengan:

$\varepsilon \quad$ : Regangan (\%)

Lo : Panjang Awal Spesimen (mm)

L : Panjang Akhir Spesimen (mm)

Tabel 2. Data hasil pengujian tarik dengan arus 65A

\begin{tabular}{ccccc}
\hline \multirow{2}{*}{ Pengujian } & $\begin{array}{c}\text { Kode } \\
\text { Specimen }\end{array}$ & $\begin{array}{c}\text { Tegangan } \\
(\boldsymbol{\sigma}) \mathbf{M P a}\end{array}$ & $\begin{array}{c}\text { Regangan } \\
(\boldsymbol{\varepsilon})(\%)\end{array}$ & $\begin{array}{c}\text { Modulus Elastisitas } \\
\text { E (Gpa) }\end{array}$ \\
\hline 1 & Al-Mg 65A & 181,3 & 8,65 & 2,266 \\
2 & Al-Mg 65A & 136,26 & 2,56 & 3,649 \\
3 & Al-Mg 65A & 91,23 & 5,6 & 2,957 \\
\hline \multicolumn{2}{c}{ Rata-rata } & 136,26 & 5,603 & 2,96 \\
\hline
\end{tabular}

Tabel 3. Data hasil pengujian tarik dengan arus 70A

\begin{tabular}{|c|c|c|c|c|}
\hline Pengujian & $\begin{array}{c}\text { Kode } \\
\text { Specimen }\end{array}$ & $\begin{array}{c}\text { Tegangan } \\
(\sigma) \mathrm{MPa}\end{array}$ & $\begin{array}{c}\text { Regangan } \\
(\varepsilon)(\%)\end{array}$ & $\begin{array}{c}\text { Modulus Elastisitas } \\
\text { E (Gpa) }\end{array}$ \\
\hline 1 & Al-Mg 70A & 146,51 & 4,61 & 3,185 \\
\hline 2 & Al-Mg 70A & 116,42 & 2,5 & 4,85 \\
\hline 3 & Al-Mg 70A & 131,46 & 3,53 & 4,11 \\
\hline \multicolumn{2}{|c|}{ Rata-rata } & 131,46 & 3,55 & 4,05 \\
\hline
\end{tabular}

Tabel 4. Data hasil pengujian tarik dengan arus 75A

\begin{tabular}{ccccc}
\hline \multirow{2}{*}{ Pengujian } & $\begin{array}{c}\text { Kode } \\
\text { Specimen }\end{array}$ & $\begin{array}{c}\text { Tegangan } \\
(\boldsymbol{\sigma}) \mathbf{M P a}\end{array}$ & $\begin{array}{c}\text { Regangan } \\
(\boldsymbol{\varepsilon})(\boldsymbol{\%})\end{array}$ & $\begin{array}{c}\text { Modulus Elastisitas } \\
\text { E (Gpa) }\end{array}$ \\
\hline 1 & Al-Mg 75A & 158,46 & 5,187 & 3,11 \\
2 & Al-Mg 75A & 173,36 & 4,65 & 3,77 \\
3 & Al-Mg 75A & 165,91 & 4,92 & 3,4 \\
\hline \multicolumn{2}{c}{ Rata-rata } & 165,91 & 4,91 & 3,43 \\
\hline
\end{tabular}




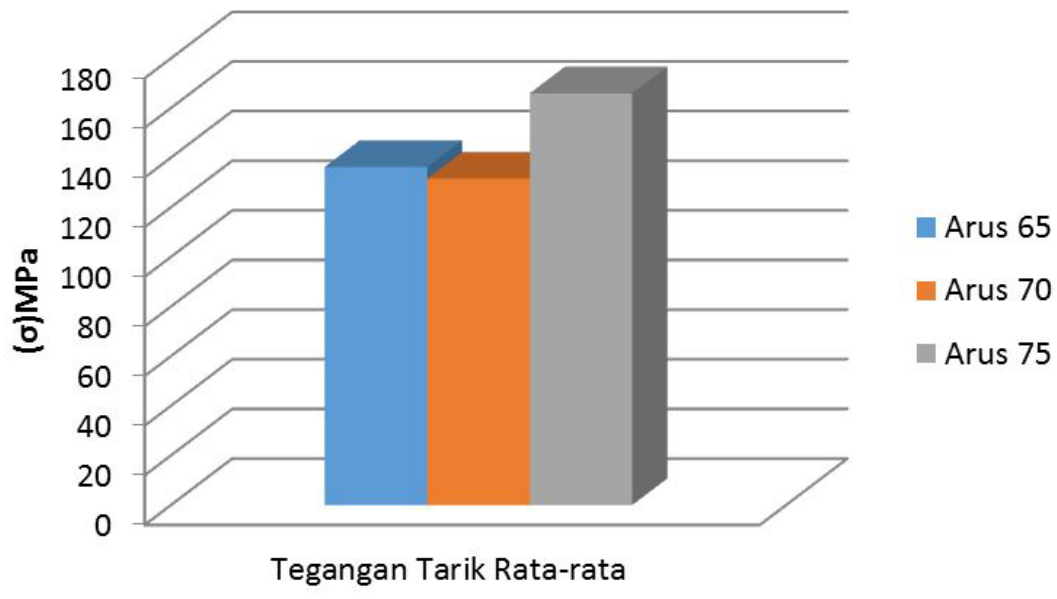

Gambar 3. Grafik tegangan tarik rata-rata

Pada pengujian tarik untuk spesimen hasil las TIG didapatkan data pengujian seperti Tabel 2, 3, 4 dan Gambar 3 di atas. Variasi kuat arus yang digunakan untuk pengelasan TIG adalah 65, 70, dan 75 A menghasilkan kekuatan tarik yang bervariasi pula. Kekuatan tarik tertinggi dihasilkan oleh plat dengan penyambungan menggunakan arus las 75A yaitu 165,91 MPa. Hal ini dikarenakan faktor arus yang digunakan pada arus 75A terjadi peningkatan sifat mekanis, selain itu juga pada saat proses pengelasan berlangsung cairan las masuk dan melebur ke tengah aluminium, sehingga menghasilkan sambungan las yang kuat.

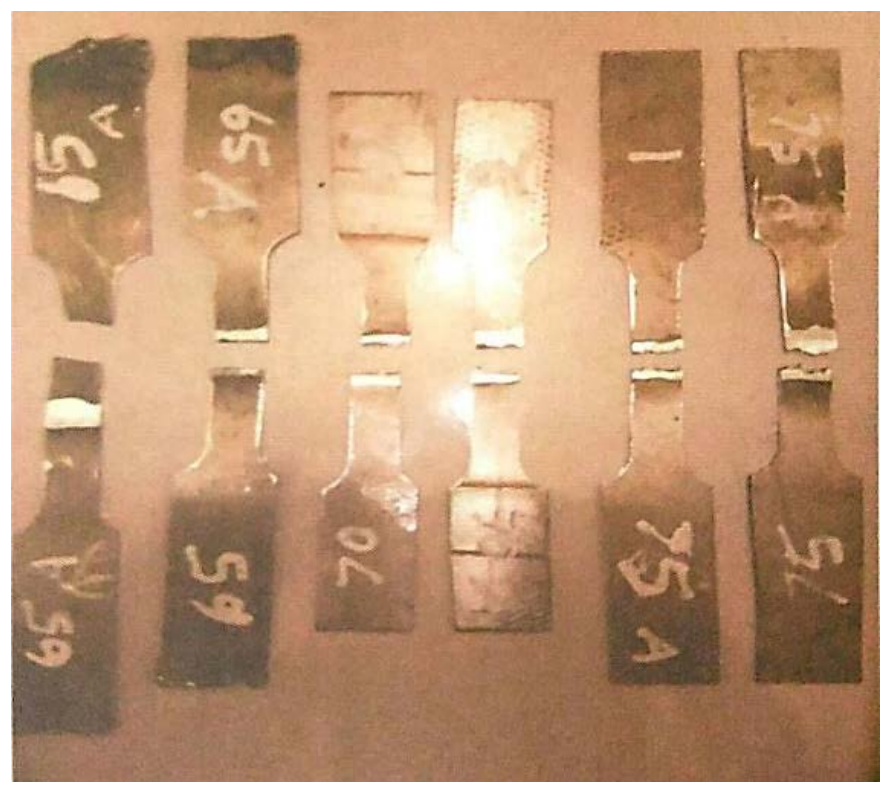

Gambar 4. Spesimen hasil uji tarik

\section{SIMPULAN}

Hasil kesimpulan yang didapat dari penelitian ini adalah bahwa proses pengelasan untuk pada pelat aluminium seri 5 dengan variasi arus pengelasan 65, 70, dan 75 A didapatkan bahwa pada pengelasan TIG dengan bahan paduan Al-Mg dilakukan dengan arus AC dikarenakan pembersihan permukaan logam yang lebih besar. Untuk pengerjaan logam bentuk pelat, pengelasan TIG dapat dilakukan tanpa filler logam. Dari pengujian komposisi bahan memperlihatkan bahwa kandungan aluminium sebesar 97,76\% dan unsur penambah utama Magnesium sebesar 1,753\%. Pada pengujian tarik, dari variasi kuat arus yang digunakan untuk menyambung pelat aluminium yaitu 65, 70, dan 75 A menghasilkan kekuatan tarik yang berbeda. Kekuatan tarik tertinggi dihasilkan pada penyambungan pelat menggunakan kuat arus 75 A dengan hasil 165,91 MPa. Hal 
ini dikarenakan dengan kuat arus 75 A menunjukkan ada peningkatan sifat mekanis, selain itu hal tersebut dikarenakan pada saat proses pengelasan cairan las masuk dan melebur ke tengah aluminium, sehingga menghasilkan sambungan las yang kuat.

\section{DAFTAR PUSTAKA}

[1]. Syaiful, 2002, Penelitian tentang Pengaruh Pengelasan Berulang Tiga Kali dan Variasi Ampere terhadap Kekuatan Tarik Material Baja ST 42, Repository Unikom.

[2]. Fiskan, Y., 2016, Pengaruh Variasi Kampu Terhadap Kekuatan Tarik Hasil Pengelasan TIG pada Baja Karbon Rendah ST 37, Skripsi Universitas Lampung, Bandar Lampung.

[3]. Anonim, 2013, Grumman Canoes, One Grumman Way P.O BOX 549 Marathon, NY 13803 Tel : 888-694-1285 • 607-849-3211 Fax: 607-428-0596 Grumman Canoes are Manufactured by Marathon ${ }^{\circledR}$ Boat Group, Inc.www.marathonboat.com.

[4]. Iskandar, F., 2013, Workshop Thetrekkers, Perahu dari bahan Aluminium untuk Wisata Air, Jl. Palagan Tentara Pelajar km. 9, Komdonen, Sariharjo, Sleman, DIY.

[5]. Davis, H.E., Troell, G.E., Hauck, G.F.W., 1982, The Testing of Engineering Materials, Editions, Mc Graw-Hill Book Company.

[6]. Wiryosumarto, H., 1976, Teknik Pengelasan Logam, Pradnyaparamita, Jakarta. 